\title{
Viral Haemorrhagic Fever (VHF) and Other Serious Viral Infections
}

\author{
First contact - how to act and protect
}

\begin{abstract}
Viral haemorrhagic fever-VHF- virus and a number of other special viruses are considered to cause the world's most dangerous infections with very high mortality, lack of therapeutic possibilities and often absence of effective vaccines. Such viruses are identified as "biohazard-level 4" agents and are treated at the highest level of infection protection with strict isolation measures. At least 14 patients with Ebola disease were transported to Europe and the United States (11 patients) for hospital treatment during the African epidemic in 2014. There were no secondary spread of VHF import cases in Europe and the United States from 1999 until the Ebola outbreak in 2014. Then there were three cases of nosocomial spread to personnel in hospitals, two in the United States and one in Spain, despite alleged use of strict containment routines. This indicates a high risk of spread of infection through intensive treatment and handling of very sick persons with VHF like Ebola. In most cases vaccines are not available or specific antiviral drugs. Therefore, infection control must be based on a proper infection protection. This chapter is focused on practical means to handle and treat patients with suspect VHF or other dangerous agents to avoid spread to personnel and environment
\end{abstract}

\section{Keywords}

Viral haemorrhagic fever · VHF · Ebola $\cdot$ Lassa $\cdot$ Other VHFs · SARS · MERS Nipah · Biohazard-level 4 agents $\cdot$ High-risk infections · Information · Infection control $\cdot$ Hygiene $\cdot$ Disinfection $\cdot$ PPE $\cdot$ Emergency $\cdot$ Transport · Admittance 


\subsection{Purpose}

- Protect healthcare professionals and close contacts against infection from blood and other body fluids in suspected or documented high-risk, dangerous infectious disease [1-18].

- Prevent spread of infection by means of infection control barriers.

- Patients or personnel should not be exposed to dangerous infections which may be serious to health or life $[19,20]$. It is not acceptable to place a patient with not defined disease in the same room as a patient with known high-risk disease (WHO).

\subsection{Comprise}

1. Patient without signs of infectious disease, but recently in the last 3 weeks from known epidemic area abroad where there is an outbreak of severe, highly infectious epidemic and

(a) Exposed to SARS or other severe acute respiratory tract infection and been in close contact with sick people with severe acute respiratory tract infection, or

(b) Exposed to VHF (Lassa,Ebola, etc.) and been in close contact with sick people with bleeding in the skin and high fever, or

(c) Exposed to bird flu and been in contact with sick birds-suspected of having bird flu

2. Patient with signs of infectious disease, recently arrived in the last 3 weeks from a known epidemic area abroad and

(a) Have symptoms of severe infection with high fever and rash/bleeding (VHF), or

(b) Have severe respiratory tract infection and been in close contact with patients with severe respiratory tract infection (e.g. SARS or MERS), or

(c) Have severe respiratory tract infection and been in direct contact with sick birds - suspected of having avian influenza

3. Personnel and others who have treated such patients - unprotected.

4. Environment and equipment, etc. which have been in contact with such patients-unprotected.

\subsection{Responsibility}

The hospital's management provides written plans for handling such cases and of that necessary resources are available.

The department management at the ambulance/emergency department, infectious medicine and anaesthetic and intensive care units must have procedures for the treatment of such patients and other key personnel who have undergone special training and necessary exercises. 
The department management admitting and handling such patients are responsible for personal protective equipment_PPE—which is:

- Easily accessible,

- Properly packaged and checked

- That personnel are trained in use and undergo courses in donning (take on) and doffing (takeoff) PPE

- That personnel receive general training in isolation regimes (see Chap. 19 on Isolation)

Personnel must use the PPE in the correct situation and properly according to routines. Possibly contact an infection control personnel for advice.

Each user of the equipment must be responsible for a proper and safe use.

\subsection{Practical Measures [16-18]}

Patients (persons) with no symptoms of infection are usually at low risk of transmitting infection to others, but are still treated with the use of PPE because of some contagiousness which may occur during incubation phases.

Patients with infection symptoms (see above) must be considered as high-risk infectors.

\subsubsection{Emergency Action-Transport of High-Risk Patient-“Ebola” Example}

Emergency/ambulance personnel are often the first who meet and take care of a patient outside hospital. The patient may have known or unknown infections. Emergency personnel should be especially aware of and handle this situation.

\subsubsection{Before You Are in Contact with the Patient: At Home, Hotel Room and Patient Room}

1. Contact the doctor in charge and ask for advice (contact infection control personnel).

2. Close access to the room/ambulance; mark the door strict isolation, and notify others present.

3. Take on the following PPE: cap, respirator (P3 mask), goggles, phantom hood that covers the head and neck, shoe covers, waterproof gown with long sleeves or overall with a hood and double gloves. Learn the order of clothing, and control each other.

4. In agreement with the doctor in charge, enter the patient room (with barrier guidance).

5. Put a regular surgical mask or P2 mask without breathing valve on the patientpreferably let the patient do this himself.

6. If possible, the patient places himself on the transport stretcher. 
7. Cover the patient's skin, sore and the entire body as much as possible during transport (e.g. bed sheet, gown, heat coat).

8. Contact the advisor in charge by phone, and ask for further assistance to which reception.

9. Avoid transport through corridors where there are other people.

10. Rooms, fixtures and everything that have been in contact with the patient are treated as infectious. The patient's equipment is left and the room is sealed until a complete disinfection is done.

\subsubsection{If You Are Already in Direct Contact with the Patient (in the Same Room at Home, Hotel Room, Patient Room) and Detect Suspected Infection “Ebola" (Unprotected) Without PPE}

PPE should be taken on before further work with the patient.

1. Do not leave the room, but walk away from the patient, and be calm and explain.

2. Hand disinfection (alcohols 70-85\%) inactivates most dangerous viruses.

3. Move right outside the patient's room and do not go elsewhere.

4. New hand disinfection. Contact the doctor in charge by phone and ask for assistance.

5. Notify others present about the need for PPE and other assistance. PPE equipment should always be ready in the ambulance-minimum for two persons.

6. Put on PPE: Gown-waterproof/overall; shoe covers; cap; phantom hood; respirator, P3 mask; goggles/visor; and two pairs of gloves (disinfect hands before wearing gloves).

7. Go back to the patient.

8. Put surgical mask or P2 mask without breathing valve on the patient, or ask the patient to put a mask on themselves. Perform calm with gentle movements so that no particles are swirled up.

9. If the patient is able to it, he will put himself on the stretcher.

10. Cover the patient's skin, sore and the entire body as much as possible during transport (e.g. bed sheet, gown, etc.).

11. Contact the doctor in charge by phone and ask for further assistance to which reception.

12. Avoid transport through corridors where there are other people.

13. Rooms, fixtures and everything that have been in contact with the patient are treated as infectious. The patient's equipment is left and the room is sealed until complete disinfection is done.

\subsubsection{PPE-Doffing (Removal of PPE) After Contact with High- Risk Patient: In Sluice or in Rooms Separate from the Patient}

1. Doffing must be checked by another person wearing PPE.

2. Wash the gloves outside with chloramine 5\%, chlorine bath 5\%,60 s; or hand disinfectant. 
3. Remove the shoe cover-carefully put it in the waste bag-and move to "clean place".

4. Remove both gloves carefully, put directly into the waste bag, and do not touch the skin.

5. Wash your hands in new chlorine bath for $60 \mathrm{~s}$ or hand disinfectant for $60 \mathrm{~s}$.

6. Put on new gloves before further doffing.

7. Remove carefully PPE in this order: gown, goggles/visor, phantom hood (if used), respiratory protection (P3 mask) and cap, and touch the areas that have been at least infected (usually backside of the body). Disinfect your hands with gloves between each procedure, and follow the written instructions, or see specifically under the infection protection regime-strict isolation. Check that used equipment does not contaminate the skin or the clothes under PPE during the doffing. Everything is placed in the waste bag (eventually separate bags for textiles, goggles etc.).

8. Finally remove the gloves and perform hand hygiene.

9. The waste bag is carefully closed and placed in a new clean waste bag that is disinfected outside with chloramine $5 \%$.

10. Wash your hands thoroughly, possibly in a new chlorine bath afterwards.

11. Change clothing that has been used under PPE. Used textiles are treated as infectious in separate textile bag marked infectious.

12. Shower with Hibiscrub (chlorhexidine soap)—body and hair-before new clothes are taken on.

13. After the transport, exposed personnel (contact with the patient without the use of PPE) should be discontinued and followed up 21 days after exposure (VHF).

\subsubsection{Transport Equipment (Ambulance, Stretcher, Wheelchair, etc.)}

1. After use in high risk situations, disinfect the equipment with chloramine $5 \%$, and optionally gas disinfect with hydrogen peroxide dry gas.

2. Use PPE during this procedure; dressing and undressing as outlined above.

\subsubsection{Blood and Other Spills of Biological Material}

1. Disinfect as usual with chloramine $5 \%$ or household chlorine.

2. Use PPE during this procedure, dressing and undressing as outlined above.

\subsubsection{Note! Prevent Spread of Infection from the Patient}

- Surgical mask or P2 mask without breathing valve is placed on the patient.

- Skin, sore, etc. are covered as much as possible during transport (e.g. put on bed sheet or plastic cover loose over the patient, but do not cover the head).

- Everything that has been in contact with the patient is treated as infectious. The same precautions as outlined above.

- It is possible to transport the patient in a separate plastic container (stretcher surrounded by plastic). 


\subsubsection{PPE: Equipment, Pre-packed, Expiration Date!}

PPE infection box: PPE-equipment for 2-8 persons; listed on outside of the box. Complete PPE sets are in the box.

- Virus impermeable gown with long arms and tight wrists. Complete overall can be used.

- Gloves with long cuff, solid, double, pulled over wrists (Note! Make sure the gloves are ok). Record expiration date.

- Hood/cap that holds the hair in place.

- Tightly sealed mask with hepafilter (P3). Record expiration date.

- "Phantom hood" with long neck covering the head and neck.

- Protective goggles that are tight to the skin and so large that you can use your own glasses inside.

- Boots or shoe covers.

- Two waste bags that can be closed.

PPE infection box or equivalent with pre-packaged PPE sets can be stored at:

- Ambulances, external

- Intensive department's isolate

- Clinical chemical department

- Infection department

- Microbiological department

- Emergency reception

- Children's section

- Emergency room

Main storage for PPE in the hospital: Should be available on a 24-h basis, but under control and rotation/replacement of infection control personnel in cooperation with Central warehouse or other local solutions.

\subsubsection{Notifications}

- Outbreak of serious high-risk infectious disease-import patient.

- Outbreak of severe, uncontrollable epidemic disease.

\subsubsection{Department's Notification Tasks}

\subsubsection{Who Should Notify?}

- Responsible physician, doctor in charge, nurse, supervisor and ambulance service

- Microbiological department (in case of specific agent/resistance/clinical data)

- Corporate health service (suspected of serious infection transferred to staff) 
- Primary health services if detected outbreaks of severe high-risk infection disease that require admission and high-risk isolation treatment at the hospital

- The Director of the National Institute of Public Health, the County Governor/ County Council and the National Public Health Authority (special infections, according to the Infection Control Act, etc.)

\subsubsection{To Whom Should It Be Notified?}

- Medical officer (isolation and treatment)

- Infection control unit

- Department management

- Hospital management (in case of death, resource-intensive measures, serious contagious epidemic situation)

- Hospital emergency preparedness group (severe contagious disease, unusual disease and major epidemic outbreak)

- The company doctor (on infection transferred to staff)

- Primary health services if detected outbreaks of serious high-risk infectious disease that can lead to infection in the population

- National Institute of Public Health, the County Governor/County Council and the National Public Health Authority (special infections, according to the Infection Control Act, etc.)

\subsubsection{Notification Method/Urgency}

By telephone, e-mail, fax and writing immediately. The message is assessed primarily by professional responsible personnel at the relevant department by extent/ severity.

\subsubsection{Meeting Place for the Emergency Preparedness Group}

The Director of the hospital leads the Emergency Group and decides when it is necessary to call the group to the Director's office. See Chap. 81 on the Preparedness Group.

\subsubsection{Actions and Responsibilities}

\subsubsection{Increased Preparedness}

The emergency preparedness group assesses the situation on a continuous basis and checks that:

- Infection isolates are available in the required amount and quality (regular air pressure control).

- A feasible plan for cohort treatment of defined infectious patients, mobilization and relocation of other patients. 
- Competent personnel available for the relevant infection control work.

- Available and adequate containment equipment (respiratory protection, gown, gloves, etc.).

- Overview of defined stocks with PPE and disinfectants.

- Actual preventive vaccines are set (flu, rabies, anthrax, BCG, diphtheria, tetanus, polio, plague, etc.).

- A plan for further treatment of infected patients and exposed personnel.

- Notify relevant laboratories and X-ray departments and other departments/contacts of the patient so that they prepare measures.

- A plan for trapping up capacity.

\subsubsection{Alarm}

The Emergency Group activates current personnel to participate in the mission.

\subsubsection{Priorities}

1. High-risk isolates are staffed by infection professionals using PPE.

2. Fastest possible diagnosis/identification of microbe (clinical examination and laboratory studies, including microbiological diagnostics).

3. Quick message to exposed persons and responsible health personnel about measures necessary around exposed cases (name, address, number of persons exposed, measures).

See Chap. 82 on scenarios

\subsubsection{Information Duty}

The Director is responsible for external information to the Director of the National Institute of Public Health, the County Governor/County Council, the National Public Health Authority (according to Infection Control Act) and the National Health Directorate and the Ministry of Health and Care.

Note! Plan your work, and do not walk outside the area of infection with PPE on! Avoid unnecessary transport! Avoid many participants!

\subsection{Background Information}

VHF virus and a number of other viruses are considered to be the world's most dangerous infection agents, with very high mortality, lack of therapeutic possibilities and often absence of effective vaccines [1-16]. These viruses are identified as "biohazard-level 4" agents and are treated at the highest level of infection protection with strict isolation measures [2-8, 11, 16-18].

There is a large travel activity to epidemic and endemic areas in the world. Many travellers are becoming sick when going abroad, and some get symptoms after 
arrival to homeland, mostly harmless infections. A few persons may return very sick or be in incubation period of more dangerous infections, when returning home. This situation may need plans for patient treatment procedures to ensure early isolation of the most serious infectious diseases, such as VHF [1-14]. Viral diseases can have a relatively long incubation times (2-21 days). Many tropical-subtropical viral diseases are transmitted through insects and animals in certain geographical areas, with small ability to spread in most European countries. However, some serious infections may be spread regardless and are especially occurring as a nosocomial problem, like the SARS, MERS and Ebola.

At least 14 patients with Ebola disease were transported to Europe and the United States (11 patients) for hospital treatment in 2014. There was no secondary spread from VHF import cases in Europe and the United States from 1999 until the Ebola outbreak in 2014. Then there were three cases of nosocomial spread to personnel in hospitals, two in the United States and one in Spain, despite alleged use of strict containment routines. This indicates that it may be a high risk of spread of infection through intensive treatment and handling of ill persons. In most outbreaks vaccines or specific antiviral drugs are not available. Therefore, infection control must be based on knowledge, proper use of PPE and disinfectants, effective infection control plan and isolation preparedness [21].

\subsubsection{Lassa Fever}

Arenavirus group, known since 1969 (in Nigeria, West Africa), mortality is 27-44\%. As a rule, it is small outbreaks [7]. Outbreak of Lassa fever is going on in WestAfrica, Nigeria in 2018; with until now: 562 confirmed cases, 144 deaths and a case fatality of $25.6 \%$ (promed-mail 18 Nov 2018).

\subsubsection{Other Haemorrhagic Viruses [16]}

Bolivian haemorrhagic fever (Machupo virus); mortality 5-30\%. Sabia virus is little known, but the CDC's laboratory infection experience with this virus is described. [8] Congo-Crimean haemorrhagic fever (CCHF) has been known since 1944 and was detected in Kosovo and Pakistan in 2001. Pakistan is an endemic area for $\mathrm{CCHF}$, and especially butchers, farm workers and persons handling animals are prone to infection via blood [22].

\subsubsection{Marburg}

Filovirus, registered since 1967 (Marburg, Republic of Congo) with mortality rate $17-20 \%$, seldom cause of disease. 


\subsubsection{Ebola Virus}

Ebola is a long filovirus, registered 1972 with mortality rate 42-89\% [1, 9, 11, 12 , 16, 23-25].

Ebola virus has subtypes: Zaire, Sudan, Ivory Coast and Reston with small genomic differences and variation in mortality. Catchers may be infected by contact with sick monkeys (gorilla), bats and several other animals and "bushmeat". The antibody level is often relatively high in this population. Vaccines have been under development for over 10 years (DNA vaccine in plasmid/adenovirus modified vaccine with Ebola antigen was worked with before 2008) but again tested and some are used now. Latest outbreaks were in Uganda (2000, 2007), Gabon (2001, 2002) and Sierra Leone, Guinea and Liberia from 2014. In 2017, Ebola virus disease caused epidemic situation in the Democratic Republic of Congo (DRC) -with until now; 356 confirmed cases, 231 deaths, 39 health care workers infected, and 34800 vaccinated. The epidemic is still going on with more than 20 new cases per 48 hours. (Promed-mail Nov 24 2018).

- The Uganda epidemic in 2000 with Ebola virus led to 428 cases and 173 deaths-40\%.

- Sierra Leone, Guinea, the Liberia epidemic in 2014 with Ebola virus resulted in 28,429 cases, of which 11,297 died (per 9.10.2015) [26]. CDC calculated an underreporting of cases by a factor of 2.5 .

A total of 876 health professionals were registered with Ebola, of which 509 died, as of July 17, 2015 (WHO). Outbreaks were caused by lack of knowledge, routines and the idea of $\mathrm{WHO}, \mathrm{CDC}$, and other organizations that the risk of transmitting infection is contact and within metre from the patient [21, 23-32].

This was also shown by the example from Norway [21, 27, 28, 32].

- In October 2014, an Ebola-infected, Norwegian physician was transferred to Norway from the Bo Ebola Clinic treatment centre in Sierra Leone, run by the Norwegian Medicines sans borders (MSB).

- The Bo Ebola Clinic opened 19 September 2014.

- Two weeks later, 2-4 October, four healthcare personnel at the Bo Clinic got Ebola; two died.

- The Norwegian Ebola case was transferred to a high-level isolate in Norway and survived.

- All four had worked together in the Bo triage area: 25-26 September.

- Standard equipment in the Bo triage area was gloves and surgical mask, because the healthcare personnel working there should hold 1-2 m distance to the patients, according to WHO and to the Norwegian Public Health Institute.

- "Then they could not be infected by droplets", said the Norwegian administrator of the centre.

- "Triage was an area to talk with the patients-little PPE's was used in order to create confidence in the local population"! 


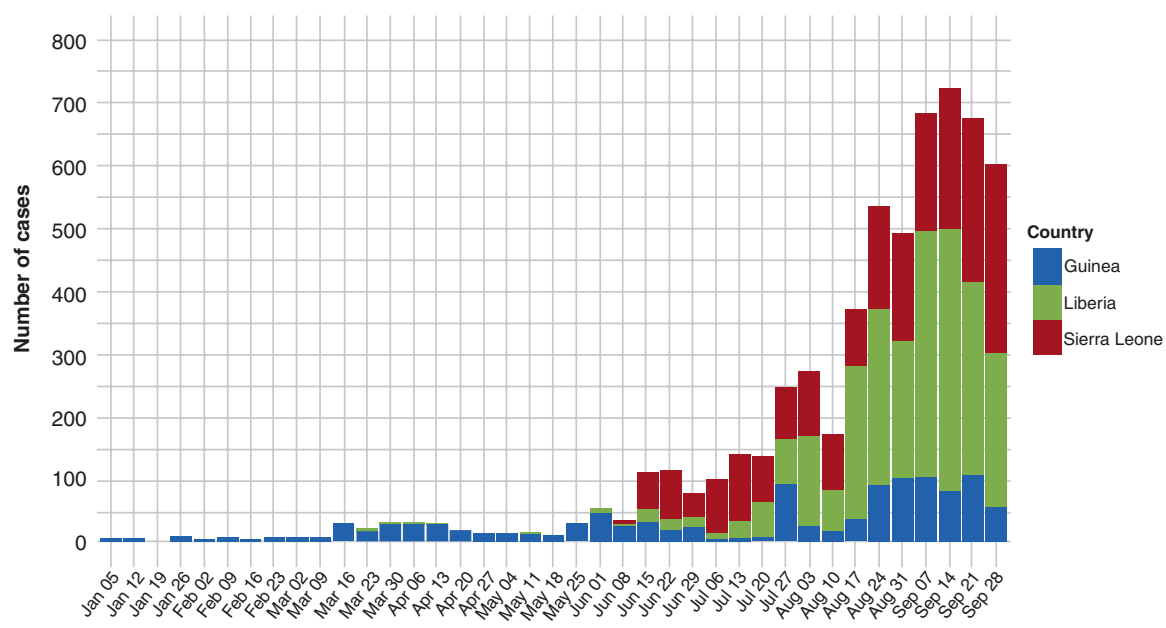

Fig. 88.1 Confirmed and probable cases of Ebola virus disease in Guinea, Liberia, Sierra Leone. Data are based on official information reported by Ministries of Health. These numbers are subject to change due to ongoing reclassification, retrospective investigation and availability of laboratory results. Source: WHO 2014

- In all, 21 health workers in the Medicines sans borders were Ebola-infected in October 2014, and 10 of them died. [27]

- Still, the Norwegian Institute of Public Health continued to follow the WHO's "1-m distance rule" for infection risk.

The epidemic had, in the beginning, a slow escalation that could have been controlled by the right means. From summer 2014, there was a rapid escalation with spreading to towns and cities (Fig. 88.1) [21, 28, 32]. Not before 8 August 2014, the WHO declared that the Ebola outbreak was a "public health emergency of international concern" (PHEIC) [28, 32]. The epidemic reached its peak 14 September 2014.

\subsection{Lack of Infection Control Routines [21, 28, 32]}

WHO, CDC and the United Kingdom established springtime 2014 guidelines for contact and droplets in a radius of $1 \mathrm{~m}$ from the Ebola patient [21, 28-32]. Outside the 1-m zone, personal protective equipment-PPE—was usually unnecessary, see Table 88.1. The spread of Ebola disease and death among many patients, including many healthcare professionals, was observed despite following WHO and CDC's guidelines [26, 28]. In 20 October 2014, CDC changed its routines for the use of PPE, focused more on training in donning and doffing PPE in sluices, use of head and neck coverings, use of P3 mask and observation of and check by a dedicated person that this work properly [33]. Healthcare staff underwent proper training in 
Table 88.1 Recommended use of infection protection equipment; PPE (personal protective equipment) in Ebola virus guidelines from the World Health Organization (WHO), United Kingdom (UK) and Centres for Disease Control and Prevention (CDC), USA (source: Andersen BM Hospital Health Care 2015; March [28, 32])

Comparison of recommended PPE equipment for Ebola infection in WHO, UK and CDC guidelines [21, 28-34]

\begin{tabular}{|c|c|c|c|c|}
\hline & $\begin{array}{l}\text { WHO } \\
2014^{\mathrm{a}} \\
\text { September }\end{array}$ & $\begin{array}{l}\text { UK } 2014^{\mathrm{b}} \\
\text { September }\end{array}$ & $\begin{array}{l}\text { CDC } \\
2014^{c} \\
\text { August }\end{array}$ & $\begin{array}{l}\text { CDC } \\
2014^{d} \\
\text { October } \\
20\end{array}$ \\
\hline \multicolumn{5}{|l|}{ Spread of Ebola infection } \\
\hline Direct contact & Yes & Yes & Yes & Yes \\
\hline Indirect contact & $?$ & Yes & Yes & Yes \\
\hline Airborne? & No & No & No & No \\
\hline \multicolumn{5}{|l|}{ Use of PPE at } \\
\hline \multicolumn{5}{|l|}{ Suspected cases of Ebola } \\
\hline Eye protection & Yes & Yes & Yes & \\
\hline Gown & Yes & $\begin{array}{l}\text { Plastic } \\
\text { apron }\end{array}$ & Yes & \\
\hline Gloves & Yes & Yes & Yes & \\
\hline Mask/surgical mask & Yes & Yes & Yes & \\
\hline $\begin{array}{l}\text { Respiratory protection/N95/P3 mask } \\
\text { etc. }\end{array}$ & No & No & No & \\
\hline Hair/head protection & No & No & No & \\
\hline Specific shoes/shoe covers & Yes & No & No & \\
\hline \multicolumn{5}{|l|}{ Confirmed cases of Ebola } \\
\hline Eye protection & Yes & Yes & Yes & Yes \\
\hline Gown & Yes & Yes & Yes & Yes \\
\hline Gloves & Yes & Yes & Yes & Yes \\
\hline Mask/surgical mask & Yes & No & Yes & No \\
\hline $\begin{array}{l}\text { Respiratory protection/N95/P3 mask } \\
\text { etc. }\end{array}$ & No & Yes & No & Yes \\
\hline Hair/head protection & No & No & No & Yes \\
\hline Specific shoes/shoe covers & Yes & No & No & Yes \\
\hline \multicolumn{5}{|l|}{ Aerosol-producing procedures } \\
\hline Respiratory protection/N95/P3 mask etc. & Yes & Yes & Yes & Yes \\
\hline Hair/head protection & No & No & No & Yes \\
\hline Specific shoes/shoe covers & Yes & No & Yes & Yes \\
\hline
\end{tabular}

${ }^{a}$ WHO. Interim infection prevention and control guidance for care of patients with suspected or confirmed filovirus haemorrhagic fever in health-care settings, with focus on Ebola. September 2014

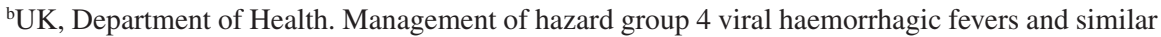
human infectious diseases of high consequences. September 2014

${ }^{\mathrm{c}} \mathrm{CDC}$. Infection prevention and control recommendations for hospitalized patients with known or suspected Ebola haemorrhagic fever in US hospitals. August 2014

${ }^{\mathrm{d}} \mathrm{CDC}$. Guidance on personal protective equipment to be used by healthcare workers during management of patients with Ebola virus disease in US hospitals, including procedures for putting on (donning) and removal. October 20, 2014 
Fig. 88.2 PPE use for Ebola virus infection. Source: http:imag.cdn2. vietnamnet.vn

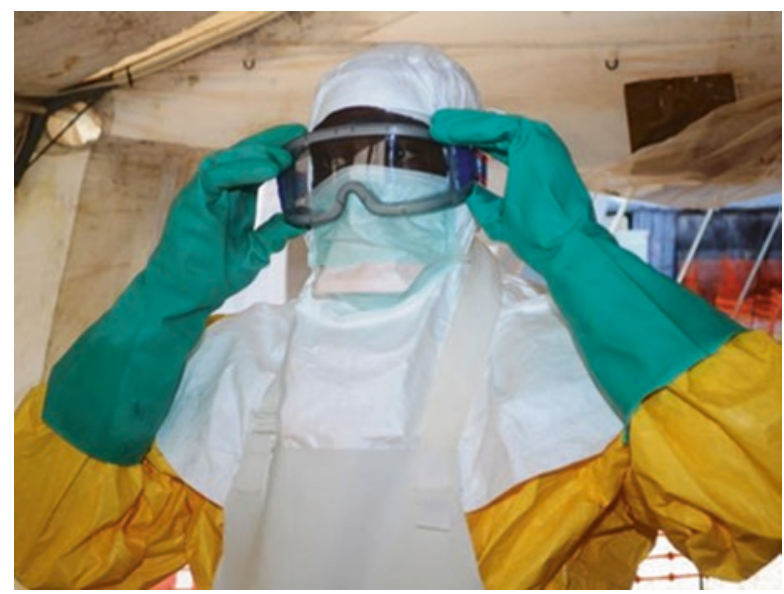

the use of PPE and other infection control measures before being sent out in the field. From January 2015, WHO also changed its schedule, but still with regular mask, with the exception of aerosol-generating procedures and still "within a meter of the patient" [34].

It is discussed whether Ebola infects via air or not; important for infection control measures [21, 28, 32]. Earlier studies have warned that air transmission cannot be excluded, as shown in animal experiments [9, 11, 16, 23-25, 35]. Based on high risk of fatal progression, preventive measures are better than belated wisdom. However, in April 2015, CDC and WHO still postulated that "Ebola is not spread through air, water or food". Since the Ebola virus may occur in large quantities in saliva and tears and mucous membranes during disease, studies generally show that drops from cough and sneezing may spread up to $9 \mathrm{~m}$ away [36].

Ebola virus survives a long time in biological materials such as blood and other body fluids/secretions (urine, semen, saliva), 9 weeks or more after onset of the disease and also post mortem [37]. Very long-lasting carrier status, and relapse of carrier status occurs even after the patient has been declared healthy. The virus may occasionally be detected in tissues in the body such as in the eye, lungs, testicleswith relapse of the infection observed several times, last with a Scottish nurse who became ill again, "Post-Ebola Syndrome" [26].

There is increasing scepticism regarding the management of the Ebola epidemic, also from the WHO internal evaluation group [38]. Airborne infection and reaerosols from equipment and bedclothes and textiles cannot be ruled out, which means that personnel and others who treat such patients must use a better protection [21, 28, 32, 39-43] (Fig. 88.2).

During formation of aerosols, including production of re-aerosols, all types of viruses can become airborne. Therefore, all high-risk virus with high mortality, "biohazard-level 4" should be treated as strict isolation-(air, contact, blood, 
secretions, tissue, etc.); the most advanced infection control regime available! There is, however, a high risk of self-contamination during PPE donning and doffing, mainly because of protocol deviations, even for doffing assistants and trained observers [32, 44-46].

\section{References}

1. Arthur RR. Ebola in Africa discoveries in the past decade. Eurosurveillance. 2002;7:33-6.

2. Crowcroft NS, Morgan D, Brown D. Viral haemorrhagic fevers in Europe-effective control requires a co-ordinated response. Eurosurveillance. 2002;7:31-2.

3. Wirtz A, Niedrig M, Fock R. Management of patients with suspected viral haemorrhagic fever and other potentially lethal contagious infections in Germany. Eurosurveillance. 2002;7:33-42.

4. Hugonnet S, Saxon H, Pittet D. Management of viral haemorrhagic fevers in Switzerland. Eurosurveillance. 2002;7:42-4.

5. Crowcroft N, Brown D, Gopal R, Morgan D. Current management of patients with viral haemorrhagic fevers in the United Kingdom. Eurosurveillance. 2002;7:44-8.

6. Swan CM, van der Broek PJ, Wijands S, van Steenbergen JE. Management of viral haemorrhagic fever in the Netherlands. Eurosurveillance. 2002;7:48-50.

7. Crowcroft N. Management of Lassa fever in European countries. Eurosurveillance. 2002;7:50-2.

8. Armstrong LR, Dembry LM, Rainey PM, Russi MB, Khan AS, Fischer SH, et al. Management of a Sabia virus-infected patient in a US hospital. Infect Control Hosp Epidemiol. 1999;20:176-82.

9. Feldmann H, Slenczka W, Klenk HD. Emerging and reemerging of filoviruses. Arch Virol Suppl. 1996;11:77-100.

10. Borio L, Inglesby T, Peters CJ, Schmaljohn AL, Hughes JM, Jahrling PB. Hemorrhagic fever viruses as biological weapons. Medical and public health management. JAMA. 2002;287:2391-405.

11. Peters CJ. Marburg and Ebola—arming ourselves against the deadly filoviruses. N Engl Med. 2005;352:2571-3.

12. Outbreak of Ebola virus disease in western Uganda. MSIS report 24/2007.

13. Duh D, Saksida A, Petrovec M, et al. Viral load as predictor of Crimean-Congo Hemorrhagic fever outcome. Emerg Infect Dis. 2007;13:1769-72.

14. Gurley ES, Montgomery JM, Hossain MJ, et al. Person-to-person transmission of Nipah virus in a Bangladeshi community. Emerg Infect Dis. 2007;13:1031-7.

15. WHO. Infection prevention and control of epidemic - and pandemic-prone acute respiratory disease in healthcare. WHO/CDS/EPR/2007.6.

16. Andersen BM. Ebola, Lassa, and other haemorrhagic viruses. In: Handbook in hygiene and infection control for hospitals. Part 1. Medical microbiology. Bergen: Fagbokforlaget; 2014. p. 291-9.

17. Andersen BM. Other serious viral infections-zoonoses. In: Handbook in hygiene and infection control for hospitals. Part 1. Medical microbiology. Bergen: Fagbokforlaget; 2014. p. 278-90.

18. Andersen BM, Hochlin K, Rasch M. Viral haemorrhagic fever (VHF) and other serious viral diseases. In: Handbook in hygiene and infection control for hospitals. Ullevål University Hospital; 2008. p. 575-82.

19. Directorate of Labor Inspection. Regulations on protection against exposure to biological factors (bacteria, viruses, fungi and more) in the workplace, December 19, 1997.

20. European Parliament and Council Directive 2000/54/EC of 18 September 2000 on the protection of workers from the risks related to exposure to biological agents at work.

21. Andersen BM. Infection control is not working. Promed-mail; 14 Sept 2014. 
22. Promed mail October 6, 2015. Crimean-Congo Haemorrhagic fever Pakistan.

23. Jahrling PB, Geisbert TW, Jaax NK, Hanes MA, Ksiazek TG, Peters CJ. Experimental infection of cynomolgus macaques with Ebola-Reston filoviruses from the 1989-1990 US. Epizootic. Arch Virol Suppl. 1996;11:115-34.

24. Mwanatambwe M, Ymada N, Arai S, et al. Ebola haemorrhagic fever (EHF): mechanisms of transmission and pathogenicity. J Nippon Med Sci. 2001;68:370-5.

25. Public Health Agency Canada. Ebola Virus; August 2014.

26. Promed mail October 9, 2015. Ebola update. WHO, Scottish nurse relapse, suspected, research, funding.

27. Olsen T. 21 health workers in medicines sans borders infected-10 died. Aftenposten; 10 Oct 2014.

28. Andersen BM. International infection control guidelines for Ebola. Hospital Healthcare Europe. Facilities management. www.hospitalhealthcare.com. Accessed April 2015.

29. WHO. Interim infection prevention and control guidance for care of patients with suspected or confirmed filovirus haemorrhagic fever in health-care settings, with focus on Ebola; Sept 2014.

30. CDC. Infection prevention and control recommendations for hospitalized patients with known or suspected Ebola haemorrhagic fever in US hospitals; Aug 2014.

31. UK, Department of Health. Management of hazard group 4 viral haemorrhagic fevers and similar human infectious diseases of high consequences; Sept 2014.

32. Andersen BM. Infection control guidelines that did not work against Ebola in 2014. www. webbertraining.com. Accessed 5 Oct 2017.

33. CDC. Guidance on personal protective equipment to be used by healthcare workers during management of patients with Ebola virus disease in US hospitals, including procedures for putting on (donning) and removal; 20 Oct 2014.

34. WHO. Steps to put on personal protective equipment (PPE) including gown. WHO 20151.

35. Weingartl HM, Embury-Hyatt C, Nfon C. Transmission or Ebola virus from pigs to nonhuman primates. Sci Rep. 2012;2:article number: 811.

36. Bourouiba L, Dehandschoewerker E, Bush JWM. Violent expiratory events: on coughing and sneezing. J Fluid Mech. 2014;845:537-63.

37. Prescott J, Bushmaker T, Fischer R, et al. Post-mortem stability or Ebola virus. Emerg Infect Dis. 2015;21:856-9.

38. WHO. Report of the Ebola Interim Assessment Panel, July 2015 to WHO.

39. Brousseau LM, Jones R. Commentary: health workers need optimal respiratory protection for Ebola. Cidrap.umn.edu. Accessed 17 Sept 2014.

40. Edmond MB, Diekema DJ, Perencevick EN. Ebola virus disease and the need for new personal protective equipment. JAMA. 2014;312(23):2495-6.

41. Shears P, O'Dempsey TJD. Ebola virus disease in Africa: epidemiology and nosocomial transmission. J Hosp Infect. 2015;90(1):1-9.

42. Weber D, Fischer WA, Wohl DA, Rutala WA. Protecting personnel from acquiring Ebola virus disease. Infect Control Hosp Epidemiol. 2015;36(10):1229-32.

43. Osterholm MT, Moor KA, Kelley NS, et al. Transmission of Ebola viruses: what we know and what we do not know, vol. 6. Minneapolis. mbio.asm.org: Centre for Infectious Disease Research and Policy, University of Minnesota; 2015. p. e00137-15.

44. Kwon JH, Burnham CD, Reske K, Liang SY, Hink T, Wallace MA, et al. Assessment of healthcare worker protocol deviations and self-contamination during personal protective equipment donning and doffing. Infect Control Hosp Epidemiol. 2017;38:1077-83.

45. Janke C, Heim KM, Steiner F, et al. Beyond Ebola treatment units: severe infection temporary treatment units as an essential element of Ebola case management during an outbreak. BMC Infect Dis. 2017;17:124.

46. Selvaraj SA, Lee KE, Harrell M, Ivanov I, Allegranzi B. Infection rates and risk factors for infection among health workers during Ebola and Marburg virus outbreaks: a systematic review. J Infect Dis. 2018;218(Suppl 5):S679-89. 